THE KURUME MEDICAL JOURNAL

Vol.33, p. 107-111, 1986

\title{
Brainstem Auditory Evoked Potentials in Basilar Artery Occlusion
}

\author{
YOSHIHIRO SATO, KATSUHIRO MIZOGUCHI, YOUSUKE SATO, \\ YASUHIRO NAKASHIMA*, TAKASHI HAYASHI** \\ AND MASARO KAJI*** \\ Department of Neurology, Clinical Laboratory* and Neurosurgery**, St.Mary's \\ Hospital and ${ }^{* * *}$ Department of Internal Medicine, Kurume University \\ School of Medicine, Kurume, 830 Japan
}

Received for publication June 2, 1986

\begin{abstract}
Summary: Brainstem auditory evoked potentials (BAEPs) were recorded in 10 patients who had basilar artery occlusions. Five patients had abnormal BAEPs during the initial recording. Among the remaining patients, three who underwent follow-up study revealed an abnormality within eight days after the onset. An abnormal CT scan preceded the abnormal BAEPs in seven patients. There were five deaths within seven days after onset; three of these patients displayed an abnormal initial BAEP and two patients had a normal initial BAEP. All five patients with abnormal initial BAEPs had severe disorders of consciousness. Abnormal BAEPs during repetitive measurements indicated the severity of the brainstem damage. Therefore, it was concluded that BAEPs are useful both for making an early diagnosis and for determining the prognosis of the basilar artery occlusion, especially when combined with a CT scan.
\end{abstract}

Key words: brainstem - auditory evoked potential - basilar artery occlusion - cerebral infarction - CT scan

\section{Introduction}

Brainstem auditory evoked potentials (BAEPs) are sensitive indicators of neoplastic, demyelinating and ischemic lesions involving auditory pathways in the pons and midbrain (Faught and Oh, 1985; Gilroy et al. 1977; Kjaer, 1980; Maurer et al. 1979; Starr and Hamilton, 1976; Stern et al. 1982). Basilar artery occlusion is often difficult to diagnose clinically in its early stage (Kubik and Adams, 1946). Recent advances in respiratory care for stroke patients has resulted in long term survival of patients with basilar artery occlusion.

The present study was undertaken to investigate a relationship between BAEPs and the clinical course, and to consider the possibility of using BAEPs in the early diagnosis of basilar artery occlusion.

\section{Material and Method}

Ten patients with basilar artery occlusion were studied. There were five men and five women, from 59 to 82 years-old (an average of 73) at the time of onset. The diagnosis was based on the results of a cranial computed tomography (CT) and on clinical characteristics, such as a severe impairment of consciousness, a decerebrate posture, quadriplegia, bilateral pyramidal signs, a disorder of extraocular muscle movement and a high fever.

BAEPs were obtained at the bedside. The audiostimulus intensity was kept at 85-dB. Potentials were recorded in response to independent stimulation of each ear. Electrodes were applied to the vertex and the mastoid. Two averaged sets of 1,024 responses were obtained from each ear. 
BAEPs were measured on all patients from one day to eight days for an initial study. Seven patients underwent a followup BAEP study. To obtain the normal ranges for interpeak latencies (IPLs), BAEPs were recorded from 10 normal subjects with a mean age of 51 years (Table 1 ). The BAEPs were evaluated for abnormalities by the following criteria; (1) At least one of the IPLs was prolonged.

(2) One of the I, III or V waves was missing.

\section{Results}

I. Correlation of the BAEP and the CT scan (Fig. 1)

Abnormal initial BAEPs were detected in five patients (cases 2, 3, 5, 9 and 10). Prolonged I-V IPLs were present in all five patients, delayed I-III IPLs in three patients and III-V IPLs in two patients.

The BAEPs from right-ear stimulation displayed an attenuation of the $\mathrm{V}$ wave in case 2. The other four patients who underwent follow - up BAEPs displayed prolonged IPLs within eight days after the onset, except one patient.

Abnormal findings on the CT scan, which suggested basilar artery occlusion, preceded the abnormal BAEPs in seven patients (cases 1, 2, 4, 6, 7, 8 and 10). The opposite was observed in the other three patients. Case 7 had prolonged I-V and III-V IPLs, although his CT scan indicated a normal brainstem with a decreased attenuation in the distribution of the bilateral occipital artery. In contrast, normal BAEPs were observed in case 1 , even though the CT scan revealed a decreased attenuation of the pons (Fig. 2,3).

II. Comparison of Patients with normal initial BAEPs and abnormal initial $B A$ EPs (Table 2, 3)

Death within seven days after onset was observed in three of five patients with abnormal initial BAEPs and two of five patients with normal initial BAEPs. All patients with abnormal initial BAEPs were comatose at the time of the examination. Also, two patients with normal initial BAEPs were drowsy or stuporous.

\section{Repeated measurements of BAEPs (Fig. $4,5)$}

Three patients with normal initial BAEPs revealed a prolongation of the I-III, III-V or I-V IPLs in follow-up studies within eight days after the onset. Three patients who were reexamind after the 10 th day had prolonged III-V IPLs in comparison to earlier recording. However, one patient underwent a normalization of the I-III IPLs.

TABLE 1

Normal values for interpeak latencies

\begin{tabular}{ccc}
\hline IP L & $\begin{array}{c}\text { Mean } \pm \text { SD } \\
(\mathrm{msec})\end{array}$ & $\begin{array}{c}\text { Normal range } \\
(\mathrm{msec}, \mathrm{M} \pm 2 \mathrm{SD})\end{array}$ \\
\hline I - III & $2.12 \pm 0.19$ & $1.74-2.50$ \\
III - V & $1.92 \pm 0.21$ & $1.50-2.34$ \\
I - V & $4.04 \pm 0.32$ & $3.40-4.68$ \\
\hline
\end{tabular}

\begin{tabular}{|c|c|c|c|c|c|c|c|c|c|c|c|}
\hline $\begin{array}{l}\text { Case } \\
\text { No. }\end{array}$ & $\begin{array}{l}\text { Age and } \\
\text { Sex }\end{array}$ & & 1 & 2 & 3 & 4 & 5 & 6 & 7 & \multicolumn{2}{|c|}{8 (Days) } \\
\hline 1 & $59 . F$ & $\begin{array}{l}\text { BAEPs } \\
\text { CT }\end{array}$ & & 0 & & & $\bullet$ & & & 8 & \\
\hline 2 & $67 . M$ & $\begin{array}{l}\text { BAEPs } \\
\text { CT }\end{array}$ & $\bullet$ & : & & & $D$ & & & & \\
\hline 3 & $82 . M$ & $\begin{array}{c}\text { BAEPs } \\
\text { CT }\end{array}$ & & : & & & & 0 & & & \\
\hline 4 & $70 . \mathrm{m}$ & $\begin{array}{c}\text { BAEPs } \\
\text { CT }\end{array}$ & o & . & 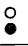 & & & & & & - (3.5 Months) \\
\hline 5 & $73, F$ & $\begin{array}{l}\text { BAEPs } \\
\text { CT }\end{array}$ & 0 & $\bullet$ & & & & & : & & \\
\hline 6 & $69 . F$ & $\begin{array}{l}\text { BAEPs } \\
\text { CT }\end{array}$ & $\begin{array}{l}\circ \\
0\end{array}$ & & $\bullet$ & & & D & & & \\
\hline 7 & $81 . F$ & $\begin{array}{l}\text { BAEPs } \\
\text { CT }\end{array}$ & $\circ$ & & & & $:$ & & & & \\
\hline 8 & $80 . F$ & $\begin{array}{c}\text { BAEPs } \\
\text { CT }\end{array}$ & & & $\bullet$ & & & 0 & & $\bullet$ & ( 11 Days ) \\
\hline 9 & $74 . M$ & $\begin{array}{c}\text { BAEPS } \\
\text { CT }\end{array}$ & 0 & & $\bullet$ & & & & & & $\begin{array}{l}-(22 \text { Days }) \\
\text { ( } 22 \text { Days) } \\
\end{array}$ \\
\hline 10 & $73 . \mathrm{M}$ & $\begin{array}{l}\text { BAEPs } \\
\text { CT }\end{array}$ & 0 & $\bullet$ & $\bullet$ & & & & - & & \\
\hline
\end{tabular}

Fig. 1. Correlation of BAEPs to CT scans.

D : Death $\circ$ : normal

- : abnormal findings 

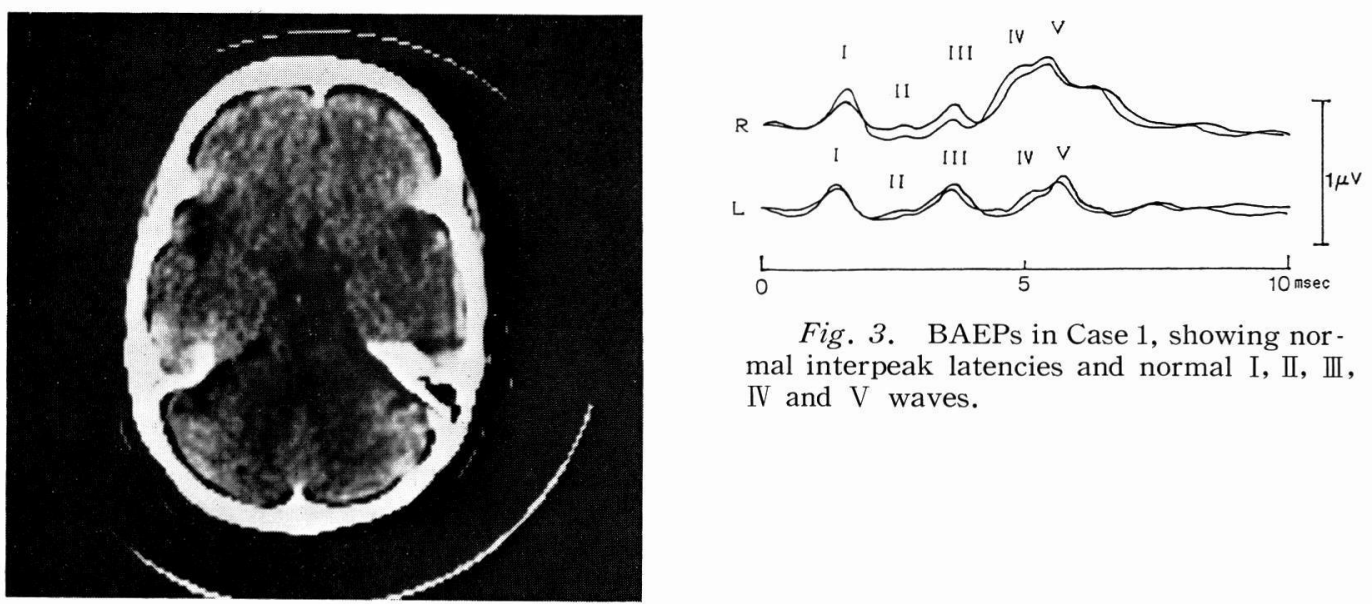

Fig. 3. BAEPs in Case 1, showing normal interpeak latencies and normal I, II, III, IV and $\mathrm{V}$ waves.

Fig. 2. A CT scan of Case 1, demonstrating decreased attenuation of the pons.

TABLE 2

Patients with normal initial BAEPs

\begin{tabular}{|c|c|c|c|}
\hline $\begin{array}{l}\text { Case } \\
\text { No. }\end{array}$ & $\begin{array}{l}\text { Level of consciou } \\
\text { the initial BAEP }\end{array}$ & $\begin{array}{l}\text { usness during } \\
\text { recording }\end{array}$ & Outcome \\
\hline 1 & Drowsiness & (7 days) & Survival ( 1 month) \\
\hline 4 & Stupor & (3 days) & Survival (11 months) \\
\hline 6 & Coma & (1 day) & Death ( 6 days $)$ \\
\hline 7 & Coma & (1 day) & Death ( 5 daya) \\
\hline 8 & Coma & (6 days) & Survival ( 8 months) \\
\hline
\end{tabular}

Case No. corresponds to Fig. 1.

TABLE 3

Patients with abnormal initial BAEPs

\begin{tabular}{|c|c|c|}
\hline $\begin{array}{l}\text { Case } \\
\text { No. }\end{array}$ & $\begin{array}{l}\text { Level of consciousness during } \\
\text { the initial BAEP recording }\end{array}$ & Outcome \\
\hline 2 & Coma (2 days) & (5 days) \\
\hline 3 & Coma（2 days) & (6 days) \\
\hline 5 & Coma (2 days) & (7 days) \\
\hline 9 & Coma (3 days) & Survival (1 month) \\
\hline 10 & Coma（3 days) & Survival (2.5 months) \\
\hline
\end{tabular}

Case No. corresponds to Fig. 1. 

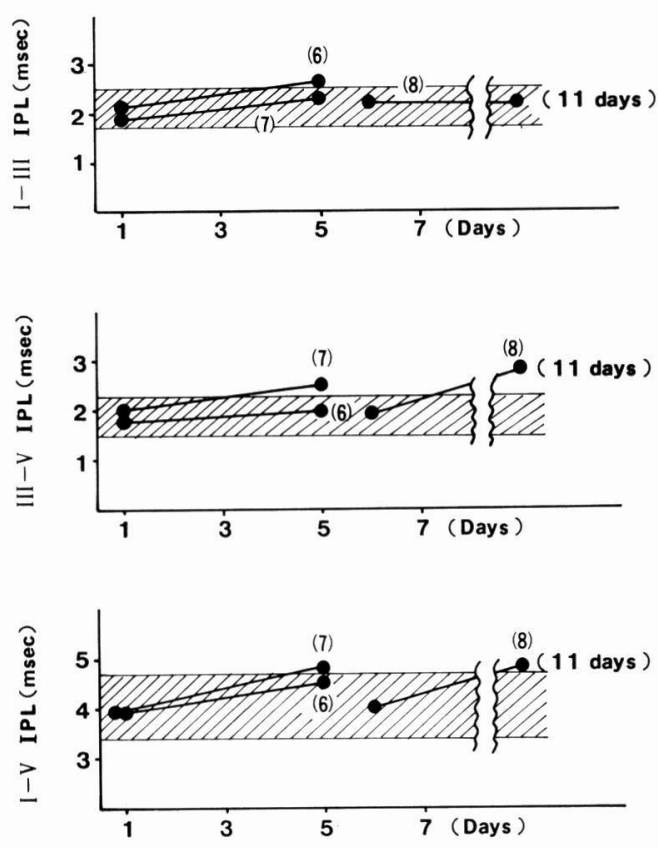

Fig. 4. Changes in BAEPs of patients who had initially normal BAEPs during the acute phase. The shaded area indicates the normal range.

\section{Discussion}

A BAEP is a sequence of five low -amplitude potentials, generated in response to a click stimulus and measured from the scalp by the farfield averaging technique. The results of animal experiments have shown that the primary generator of wave I is the cochlear nerve; wave II, the cochlear nucleus; wave III, the superior olivary nucleus; wave IV, the ventral nucleus of lateral lemniscus or the inferior colliculus; and wave V, the inferior colliculus (Hashimoto, 1983).

Several investigators have studied the BAEPs in patients with brainstem vascular disorders. Abnormal BAEPs were reported in many cases with brainstem infarction and vertebro basilar insufficiency (Faught and Oh, 1985; Maurer et al. 1979; Rossi et al. 1983). Although abnormal BAEPs were reported in a few cases with basilar
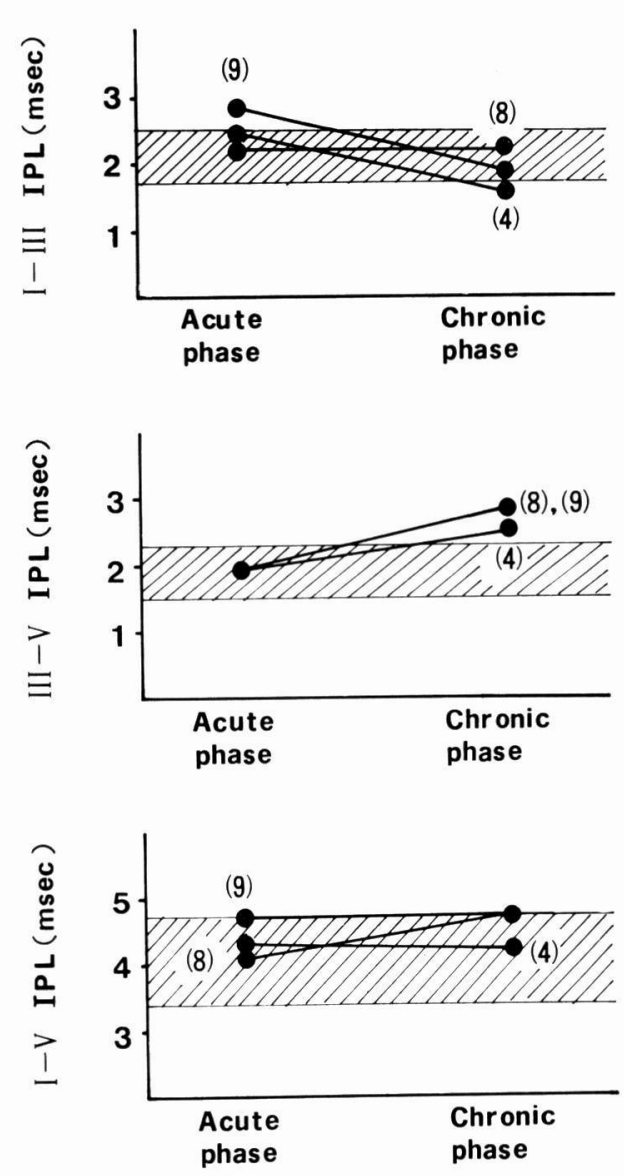

Fig. 5. Changes in BAEPs from the acute to the chronic phase. The acute and chronic phases are the first six days and after 10 days, respectively. The shaded area indicates the normal range.

artery occlusion (Kaji et al. 1985), a systematic study had not been conducted in this disease.

In the present study, half the patients had abnormal initial BAEPs within three days after onset. Three of the five remaining patients who had normal initial BAEPs developed abnormal BAEPs in a follow-up study within eight days. From these findings, BAEPs appear effective in making an early diagnosis of basilar artery occlusion.

Abnormal CT scans developed before 
the abnormal BAEPs in many of the cases. But it shoud be noted that the BAEP in one patient had prolonged IPLs despite an intact brainstem as indicated by the CT scan. In the evaluation of a patient with a severe alteration of consciousness from an unknown cause, the combination of a normal CT scan and an abnormal BAEP suggests basilar artery occlusion, and normal BAEPs and CT scans imply a metabolic encephalopathy (Stockard et al. 1980).

In general, predicting the outcome of basilar artery occlusion relies on the degree of consciousness. A catastrophic outcome during the acute phase was observed in five of eight patients who were in a coma. Our findings indicate that BAEPs have an early prognostic value in basilar artery occlusion. Furthermore, patients in a coma had a higher incidence of abnormal initial BAEPs than patients in drowsy or stuporous states of consciousness.

In brainstem vascular disorders such as brainstem infarction or vertebro basilar insufficiency, a reversibility of the BAEPs has been reported (Kaji et al. 1985; Ragazzoni et al. 1982; Rossi et al. 1983). Contrary to this, the present study indicated that no such reversibility of BAEPs occurs in the chronic state. The irreversibility of BAEPs may be a reflection of the severe damage of the brainstem.

\section{References}

FAUGHT, E. and OH, S. J. (1985). Brainstem auditory evoked responses in brainstem infarction. Stroke, 16, 701-705.

Gilroy, J., Lynn, G.E., Ristow,G.E. and Pellerin, R. J. (1977). Auditory evoked brain stem po- tentials in a case of "locked-in" syndrome. Arch. Neurol. 34, 492-495.

Наsнiмото, I. (1983). Generators of brainstem auditory evoked potentials and surgical applications. Neurol. Med. (Tokyo), 18, 209-216.

KajI, R., McCormick, F., Kameyama, M. and $\mathrm{N}_{\text {I- }}$ NomiYA, H. (1985). Brainstem auditory evoked potentials in early diagnosis of basilar artery occlusion. Neurolgy (Minneap), 35, 240-243.

KJAER, M. (1980). Localizing brain stem lesions with brain stem auditory evoked potentials. Acta Neurol. Scandinav. 61, 265-274.

Kubik, C. S. and Adams, R.D. (1946). Occlusion of the basilar artery: a clinical and pathological study. Brain, 69, 6-121.

MaUrer, K., Marneror, A., SchÄfer, E. and LeITNER, H. (1979). Early auditory evoked potentilas (EAEP) in vertebral basilar insufficiency. Arch. Psychiat. Nervenkr. 227, 367-376.

Ragazzoni, A., Amantini, A., Rossi,L., Pagnini, P., Arnetoli, G., Marini, P., Nencioni, C., Versari, A. and ZAPPOLI, R. (1982). Brainstem auditory evoked potentials and vertebral-basilar reversible ischemic attacks. Ed. Courjon, J., Mauguiére, F. and Revol, M., Advance in Neurology, vol. 32, Clinical Applications of Evoked Potentials in Neurology, pp. 187-194, New York; Raven Press.

Rossi, L., Amantini, A., Bindi, A., Pagnini, P., ARNETOLI, G. and ZAPPOLI, R. (1983). Electrophysilogical investigations of the brainstem in the vertebrobasilar reversible attacks. Eur. Neurol. $22,371-379$.

Starr, A. and Hamilton, A.E. (1976). Correlation between confirmed site of neurological lesions and abnormalities of far-field auditory brainstem responses. Electroencephalogr. Clin. Neurophysiol. 41, 595-608.

Stern, B. J., Krumholz, A., Weiss, H.D., Goldstein, P. and HARRIS, K.C. (1982). Evaluation of brainstem stroke using brainstem auditory evoked responses. Stroke, 13, 705-711.

Stockard, J. J., Stockard, J.E. and Sharbrough, F.W. (1980). Brainstem auditory evoked potentials in neurology. Ed. Aminoff, M. J., Electrodiagnosis in Clinical Neurology, New York; Churchill Livingstone. 